\title{
Condensed Matter Field Theory
}

\author{
Alexander Altland and Ben Simons
}




\section{Contents}

1 From particles to fields 1

1.1 Classical harmonic chain: phonons 3

$\begin{array}{ll}1.2 & \text { Functional analysis and variational principles } \\ 1\end{array}$

$\begin{array}{ll}1.3 \text { Maxwell's equations as a variational principle } & 16\end{array}$

$\begin{array}{ll}1.4 \text { Quantum chain } & 19\end{array}$

$\begin{array}{ll}1.5 & \text { Quantum electrodynamics } \\ 1.6 & 25\end{array}$

$\begin{array}{lll}1.6 & \text { Noether's theorem } & 31\end{array}$

1.7 Summary and outlook 34

$\begin{array}{lll}1.8 & \text { Problems } & 35\end{array}$

2 Second quantization $\quad 39$

2.1 Introduction to second quantization 40

2.2 Applications of second quantization $\quad 50$

$\begin{array}{lll}2.3 & \text { Summary and outlook } & 82\end{array}$

$\begin{array}{lll}2.4 & \text { Problems } & 83\end{array}$

3 Feynman path integral $\quad 94$

3.1 The path integral: general formalism 94

3.2 Construction of the path integral 96

3.3 Applications of the Feynman path integral 112

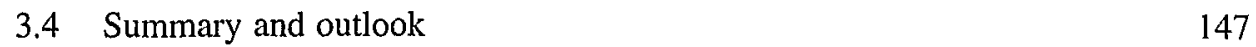

$\begin{array}{lll}3.5 & \text { Problems } & 147\end{array}$

4 Functional field integral $\quad 157$

4.1 Construction of the many-body path integral 159

4.2 Field integral for the quantum partition function 166

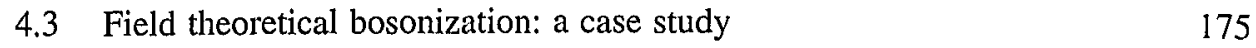

$\begin{array}{lll}4.4 & \text { Summary and outlook } & 183\end{array}$

$\begin{array}{lll}4.5 & \text { Problems } & 183\end{array}$ 
5 Perturbation theory 195

5.1 General structures and low-order expansions 196

5.2 Ground state energy of the interacting electron gas 211

$\begin{array}{ll}5.3 & \text { Infinite-order expansions } \\ 5.4 & 225\end{array}$

5.4 Summary and outlook 235

$\begin{array}{ll}5.5 \text { Problems } & 236\end{array}$

6 Broken symmetry and collective phenomena $\quad \mathbf{2 4 6}$

$\begin{array}{ll}6.1 \text { Mean-field theory } & 247\end{array}$

6.2 Plasma theory of the interacting electron gas 247

6.3 Bose-Einstein condensation and superfluidity 256

$\begin{array}{ll}6.4 \text { Superconductivity } & 270\end{array}$

6.5 Field theory of the disordered electron gas 310

6.6 Summary and outlook 338

$\begin{array}{lll}6.7 \text { Problems } & 340\end{array}$

7 Response functions $\quad \mathbf{3 7 0}$

$\begin{array}{ll}7.1 \text { Crash course in modern experimental techniques } & 370\end{array}$

$\begin{array}{lll}7.2 & \text { Linear response theory } & 378\end{array}$

7.3 Analytic structure of correlation functions 382

7.4 Electromagnetic linear response $\quad 400$

$\begin{array}{lll}7.5 & \text { Summary and outlook } & 410\end{array}$

$\begin{array}{lll}7.6 & \text { Problems } & 410\end{array}$

8 The renormalization group $\quad 419$

8.1 The one-dimensional Ising model 422

8.2 Dissipative quantum tunneling 433

8.3 Renormalization group: general theory 441

8.4 RG analysis of the ferromagnetic transition 456

8.5 RG analysis of the nonlinear $\sigma$-model 469

8.6 Berezinskii-Kosterlitz-Thouless transition 476

$\begin{array}{ll}8.7 & \text { Summary and outlook } \\ 8.8 & 487\end{array}$

8.8 Problems 489

9 Topology $\quad \mathbf{5 1 1}$

9.1 Example: particle on a ring $\quad 512$

$\begin{array}{ll}9.2 \text { Homotopy } & 517\end{array}$

$\begin{array}{lll}9.3 \text { - } & \text {-Terms } & 521\end{array}$

9.4 Wess-Zumino terms 553

9.5 Chern-Simons terms $\quad 588$

$\begin{array}{ll}9.6 & \text { Summary and outlook } \\ 9.7 & 607\end{array}$

$\begin{array}{lll}9.7 & \text { Problems } & 608\end{array}$

Index 